\title{
A Study of Short Term Follow up of Uncemented Total Hip Arthroplasty
}

\author{
Sachin Sharma ${ }^{1 *}$, Tanmay Jaysingani ${ }^{1}$, Kishan Zinzuwadia ${ }^{1}$ and Hemant Mathur ${ }^{2}$ \\ ${ }^{1}$ Resident Doctor, Department of Orthopedics, Baroda Medical College and S.S.G. Hospital, Vadodara, India \\ ${ }^{2}$ Head of Department, Department of Orthopedics, Baroda Medical College and S.S.G. Hospital, Vadodara, India \\ *Corresponding Author: Sachin Sharma, Resident Doctor, Department of Orthopedics, Baroda Medical College and S.S.G. Hospital, \\ Vadodara, India.
}

Received: November 05, 2019; Published: November 27, 2019

DOI: $10.31080 /$ ASOR.2019.02.0125

\begin{abstract}
Background: Total hip arthroplasty is one of the most common surgery performed in the world today. There are numerous prosthesis in the market and it is often difficult to choose between them. It is therefore necessary to have a good understanding of basic scientific principles of total hip arthroplasty and the evidence base underpinning them. The purpose of the study was to evaluate the results of short term follow up of patients of total cement less hip arthroplasty using Modified Harris Hip Score.

Methods and Findings: A cohort of 25 patients operated watchmates total hip arthroplasty were included. The average postoperative score for the patients was 97.85 .

Conclusion: From this study, we have concluded that operative treatment for various hip disorders in the form of cement less total hip arthroplasty has helped in alleviation of intractable pain, resumption of ambulation and return to functional activity.

Keywords: Cement less Total Hip Arthroplasty; Modified Harris Hip Score
\end{abstract}

\section{Introduction}

Total hip arthroplasty (THA) is one of the most successful orthopaedic procedure performed now a days. For patients with hip arthritis due to variety of conditions, THA can relieve pain, can restore function and can improve the quality of life. THA is a procedure whereby the diseased articular surfaces are replaced with synthetic materials thus relieving pain and improving joint kinematics and function $[1,2]$.

With introduction of the Charnley low friction arthroplasty, acrylic cement became the standard for femoral fixation. Charnley systematically promoted THA based on the concept of low friction arthroplasty by (a) fixation with bone cement; (b) adoption of a $22 \mathrm{~mm}$ femoral head; (c) adoption of ultra high molecular weight polyethylene; (d) preparation of a manual of the surgical procedures $[3,4]$.

THA procedures require the surgeon to be familiar with many technical details of operation. To contend successfully with the many problems that occur and to evaluate new concepts and implants, a working knowledge of biomechanical principles, materials and design also is necessary.

\section{Materials and Methods}

This study focuses on short term outcome of uncemented total hip arthroplasty. The observational prospective study was conducted at tertiary care hospital between Jan 2016 to Jan 2019.25 patients who were operated for uncemented THA were enrolled in the study.

A detailed history was taken regarding name, age, sex, occupation, chief complaints, pain, limp, severity of pain, duration of symptoms any treatment taken before(which may be in form of steroids or herbal medications) and any comorbid conditions(diabetes mellitus, cardiopulmonary diseases) and any haematological diseases(sickle cell disease).Personal history regarding alcohol intake was elicited. Physical examination was done including spine and upper and lower extremities and thorough local examination was done.

An anteroposterior view of the pelvis showing proximal femur and a lateral view of the hip and proximal femur were taken. Preoperative work up including including total counts, differential counts, ESR, serum CRP, serum RA, sickle solubility test, renal function test, random blood sugar, chest radiographs, ECG,2-D ECHO and pre an- 
aesthetic check up was done. Preoperatively patients were encouraged to do active quadriceps exercises. Preoperative traction was maintained for correction of deformity and to decrease spasm and pain, in cases where it was indicated. General anaesthesia or regional anaesthesia were used for the surgery. In our study we used posterolateral approach (modified Gibson's approach). Postoperatively prophylactic antibiotic in the form of intravenous injection of etoperidone and sulbactam twice a day dosage in the strength of $1.5 \mathrm{gm}$ for a minimum of 5 days was given. Negative suction drain was removed 3 days after the surgery. Sutures were removed on 10th-14th after surgery routinely depending on the status of the dressing and the local part. All patients received prophylaxis for deep vein thrombosis with tab. Rivaroxaban $5 \mathrm{mg}$ for 15 days from the day of surgery. Static and active quadriceps exercises were begun on the same evening within the limits of comfort followed by high sitting on the day of drain removal. On second postoperative day active quadriceps exercises were taught followed by non weight bearing crutch walking using walker for a period of 3 weeks. Full weight bearing without support was started at 6-8 weeks post-operatively. Follow up visits were made at 3 months, 6 months and 1 year and periodically thereafter. The functional outcome was assessed using Modified Harris Hip score.

\section{Observation and Results}

25 patients operated for uncemented THA were included in the study.

\section{Age distribution}

Age distribution of the patients included in the study has been shown in table 1.

\begin{tabular}{|l|c|c|}
\hline Serial Number & Age Group (In Years) & Number of Patients \\
\hline 1 & $0-10$ & 0 \\
\hline 2 & $11-20$ & 2 \\
\hline 3 & $21-30$ & 5 \\
\hline 4 & $31-40$ & 6 \\
\hline 5 & $41-50$ & 7 \\
\hline 6 & $51-60$ & 4 \\
\hline 7 & 61 and above & 1 \\
\hline & TOTAL & 25 \\
\hline
\end{tabular}

Table 1: Age distribution of the patients.

\section{Sex distribution}

Sex distribution of the patients has been shown in table 2 .

\section{Occupation of patients}

Occupation of the patients included in the study has been shown in the table 3 .

\begin{tabular}{|l|c|c|}
\hline Sex & Number of Patients & Percentage (\%) \\
\hline Males & 15 & 60 \\
\hline Females & 10 & 40 \\
\hline Total & 25 & 100 \\
\hline
\end{tabular}

Table 2: Sex distribution of the patients.

\begin{tabular}{|l|c|c|}
\hline $\begin{array}{c}\text { Occupation/Level of } \\
\text { Activity }\end{array}$ & Number of Patients & $\begin{array}{c}\text { Percentage } \\
\text { (\%) }\end{array}$ \\
\hline $\begin{array}{l}\text { Highly Physically } \\
\text { Active }\end{array}$ & 10 & 40 \\
\hline Moderately Active & 13 & 52 \\
\hline Low Activity Patients & 2 & 8 \\
\hline Sedentary Patients & 0 & 0 \\
\hline
\end{tabular}

Table 3: Occupation of the patients.

Indications for tha

The various indications for which the patients were operated for THA has been shown in table 4 .

\begin{tabular}{|l|c|c|}
\hline Indications & Number of Patients & Percentage \\
\hline (A)Avascular Necrosis & & \\
Idiopathic & 9 & - \\
Steroid Induced & - & 12 \\
Post Traumatic & 4 & 8 \\
Sickle Cell Disease & 1 & - \\
Alcohol Induced & 17 & 68 \\
Total & & \\
\hline (B)Arthritis & 1 & 4 \\
Ankylosing & & 12 \\
Spondylitis & 3 & 16 \\
Rheumatoid & & 16 \\
Arthritis & 4 & \\
Total & 4 & \\
\hline (C)Cases Of Implant Failure & 25 & \\
\hline Grand Total & & \\
\hline
\end{tabular}

Table 4: Indications for THA.

\section{Associated systemic diseases}

Number of patients affected by various systemic diseases has been shown in table 5 .

\section{Type of Prosthesis}

In all patients, the type of femoral and acetabular prosthesis was uncemented, either coral with duraloc system or solution 
stems or pinnacle hip systems or ceramic on ceramic type. Of the 25 patients cement less total hip arthroplasties performed in our study, 2 patients were of ceramic on ceramic variety, 1 patient was treated with solution femoral reconstruction system and 3 patients were treated with pinnacle hip system while remaining 19 patients were treated with corail duraloc hip systems.

\begin{tabular}{|l|c|}
\hline Systemic Diseases & Number of Patients \\
\hline Nil & 14 \\
\hline Hypertension & 4 \\
\hline Diabetes Mellitus & 1 \\
\hline Ankylosing Spondylitis & 1 \\
\hline Sickle Cell Disease & 4 \\
\hline Alcoholism & 1 \\
\hline
\end{tabular}

Table 5: Associated systemic diseases.

\section{Postoperative complications}

Various postoperative complications encountered have been shown in table 6.

\begin{tabular}{|l|c|c|}
\hline Complications & Number of Patients & Percentage \\
\hline Early & & \\
\hline Nerve Injury & 1 & 4 \\
\hline Vascular Injury & 0 & - \\
\hline Dvt & 1 & 4 \\
\hline Fracture & 0 & - \\
\hline Postoperative Dislocation & 2 & 8 \\
\hline $\begin{array}{l}\text { Acute Postoperative } \\
\text { Infection }\end{array}$ & 1 & 4 \\
\hline Late & & \\
\hline Subsidence & - & - \\
\hline
\end{tabular}

Table 6: Complications.

\section{Functional outcome}

Functional outcome according to Modified Harris Hip score has been shown in table 7 .

\begin{tabular}{|l|c|c|c|}
\hline Serial Number & Score & Number of Patients & Result \\
\hline 1 & $90-100$ & 24 & Excellent \\
\hline 2 & $80-89$ & 1 & Good \\
\hline 3 & $70-89$ & 0 & Fair \\
\hline 4 & $<70$ & 0 & Poor \\
\hline
\end{tabular}

Table 7: Result according to Modified Harris Hip score.

The average postoperative score for the patients was 97.85 .

\section{Discussion}

In our study, average age of patients was 40 years. $68 \%$ of the patients were operated for indication of avascular necrosis of femoral head and 16\% were operated for hip arthritis. 15 cases had neutral position of femoral component and 10 cases had valgus position of femoral component. Average follow up period was 19 months. In follow up period, 2 patients had slight pain, 6 patients used cane for long walk distance, 5 patients were able to walk for 1 kilometre and rest were able to walk unlimited. 4 patients were using railing for climbing staircase and all the patients were able to sit comfortably, able to wear shoes and socks easily and were able to use public transport. Preoperatively 10 cases had fixed flexion deformity,12 cases had adduction deformity and 5 cases had abduction deformity but there was no postoperative deformity. The range of motion score of all the patients was 5 except 1 patient who had score of 4.2 patients had slight occasional pain at the final follow up of this study. There were no abnormal radiological findings on final follow up in all patients [5-10].

\section{Conclusion}

The present study was aimed at evaluating the results of cement less total hip arthroplasty in Indian population, performed at our institute involving a strict preoperative, intraoperative and postoperative protocol. From this study, we have concluded that operative treatment for various hip disorders in the form of cementlesstotal hip arthroplasty has helped in alleviation of intractable pain, resumption of ambulation and return to functional activity. The longevity of the cementlessarthroplasty systems, their usefulness in overcoming the pitfalls of cemented total hip arthroplasties like the short duration of implant life, osteolysis and bone loss, subsequently needing revision surgeries at a later date, which are complicating and do not always yield satisfactory results, the excellent short and medium term outcome of cement less total hip arthroplasty in young active as well as older individuals, have decreased the chances of failures. In Indian population, avascular necrosis of hip is the main indication for this surgery.

No benefits or funds were received in support of this study.

\section{Bibliography}

1. Daras M and Macaulay W. "Total hip arthroplasty in young patients with osteoarthritis". American Journal of Orthopedics 38 (2009):125-129.

2. CornellCN and Ranawat CS. "Survivorship analysis of total hip replacements: results in a seriesof active patients who were less than fifty-five years old". The Journal of bone and joint surgery American 68 (1986):1430-1434. 
3. Sochart DH and Porter ML. "The long term results of Charnley low friction arthroplasty in young patients who have congenital dislocation, degenerative osteoarthrosis or rheumatoid arthritis". The Journal of bone and joint surgery American 79 (1997): 1599-1617.

4. Hartofilakidis G., et al. "The 20year outcome of the Charnley arthroplasty in younger and older patients". Clinical Orthopaedics 434 (2005): 177-182.

5. Kim YH., et al. "Primary total hip arthroplasty with a second generation cementless total hip prosthesis in patients younger than fifty years of age". The Journal of bone and joint surgery American 85 (2003): 109-114.

6. Eskelinen A., et al. "Uncemented total hip arthroplasty for primary osteoarthritis in young patients: a mid to long term follow up study from the Finnish Arthroplasty". Acta Orthopaedica 77 (2006): 57-70.

7. D' Antonio JA., et al. "Hydroxyapatite femoral stems for total hip arthroplasty:10 to 13 year follow up". Clinical Orthopaedics 393 (2001):101-111.

8. Digas G., et al. "Highly cross-linked polyethylene in cemented THA: randomized study of 61 hips". Clinical Orthopaedics 417 (2003): 126- 138.

9. Urban JA., et al. "Ceramic on polyethylene bearing surfaces in total hip arthroplasty: seventeen to twenty one yearresults". The Journal of bone and joint surgery American 83 (2001) 1688-1694.

10. Dorr LD., et al. "Total hip arthroplasty with use of the Metasul metal on metal articulation: four to seven year results". The Journal of bone and joint surgery American 82 (2000):789798.

Volume 2 Issue 12 December 2019

(C) All rights are reserved by Sachin Sharma., et al. 